\title{
1 Resilient science: The civic epistemology of Disaster Risk Reduction
}

\section{Amy Donovan}

\section{Clive Oppenheimer}

\section{Department of Geography, University of Cambridge}

\section{Abstract}

6 In this paper, we use science studies to elucidate the nature of advisory science in the context of

7 disasters, particularly those involving geophysical hazards. We argue that there are some key

8 differences between disaster advisory science and the issues that are most discussed in Science

9 Studies: they are both time- and space- specific and they constitute major social, economic, and scientific shocks. We suggest that disasters require flexible advisory structures that maximise the co-

11 production of science and social order, and present a framework for this. We argue that the aim of

12 increasing resilience to natural hazards requires that sociology of scientific knowledge play a part in

13 the application of scientific advice: disaster studies has focussed on the reduction of vulnerability as

14 a reaction against technical-rational models of scientific advice, but in doing so has restricted the

15 potential role of the social sciences in the framing of scientific advice and expertise.

\section{Introduction}

In November 2012, an Italian court found six scientists and a local official guilty of manslaughter for misinforming the public about seismic risk in L'Aquila, where a devastating earthquake occurred on $6^{\text {th }}$ April, 2009. This verdict was received with much concern in the scientific community, with many organisations condemning it as detrimental to the willingness of scientists to act as policy advisors an increasingly important part of their work (e.g. Marzocchi, 2012). The verdict reflects on a 
breakdown in the risk communication process - perhaps, as some have alleged, because of political interference in the advice that was given (Hall, 2011). Other shortcomings appear to have been a lack of transparency, a failure by the scientists and officials to regard the public as an intelligent entity, and the absence of adequate governance structures with clear remits (see Alexander, 2010 and 2013a for detailed critiques of the disaster management policies in Italy).

There are also important lessons from L'Aquila regarding the positionality of scientists in disasters.

This is particularly relevant to geophysical hazards (defined here as earthquakes and volcanic eruptions), since the level of uncertainty involved in the management of their associated impacts is very high and there is heavy dependence on scientific advice, sometimes over periods of decades (e.g. Donovan et al., 2013). By one estimate, the probability that the small earthquakes preceding the L'Aquila earthquake were foreshocks (i.e. would be followed by a larger earthquake) was less than one percent (Marzocchi, 2012). Such events were discussed in the UK Government's Blackett Review of High Impact Low Probability Risks (Government Office for Science, 2011), which placed strong emphasis on the involvement of external experts in the policy process. In extreme events, however, advisory committees may be formed ad hoc (e.g. Donovan et al., 2013; Newhall and Punongbayan, 1996; Aspinall et al., 2002), and their remit and responsibilities may not be well defined. Furthermore, as demonstrated in Italy, the legal responsibilities and accountabilities of scientists are problematised (e.g. Marzocchi, 2012; Aspinall, 2011). While scientists have generally condemned the verdict, there are also disagreements about "best practice" both within seismic hazard assessment (notably between advocates of probabilistic analysis and those who prefer deterministic methods) and in the act of providing scientific advice. studies literature: the diverse mechanisms, institutions and epistemologies involved in the provision of scientific advice and its integration with local knowledge, particularly in the context of high 
Italian case has highlighted the vulnerability of experts when both uncertainty and the stakes are high. It has demonstrated the pivotal nature of the relationships between expert advisors and social and political structures in emergencies and demonstrated that these can be significantly disordered and reordered by the activity of the Earth, with costly social consequences. This can extend the recovery time post-disaster, and understanding these relationships may aid future disaster risk reduction.

The murky epistemological status of advisory science has been addressed in the Science Studies literature in the context of the co-production of knowledge by science and society (e.g. Jasanoff, 2004; Doubleday, 2007). The co-production idiom is able to negotiate between the social construction of science and the realist view of science, by examining the ways in which knowledge production is linked to its context. Co-production has local echoes; it is closely tied into grounded practice and governance systems (Jasanoff, 2004, 2005). In response to risks, particularly low probability, high impact risks, the process of knowledge production changes as a result of sudden societal need, requiring intense collaboration between scientists and society (both political officials and the public). This is one of the key challenges in managing sudden-onset natural crises such as earthquakes and volcanic eruptions, and depends on institutional structures, relationships between different groups and the development of the crisis as defined by the earth system.

Accepting that the natural and the social world are produced together requires new approaches to the understanding of "knowledge". In her 2005 work, Designs on Nature (Jasanoff, 2005), Sheila Jasanoff presents the concept of "civic epistemology": deploy knowledge claims used as a basis for making collective choices...these collective knowledge-ways ... are distinctive, systematic, often institutionalised, and articulated through practice rather than in formal rules (p255). 
Jasanoff presents a framework through which different cultural knowledge-ways can be examined and analysed, using examples from biotechnological discourses in the UK, US and Germany. She analyses six "dimensions" of civic epistemology - styles of public knowledge-making; public accountability; public demonstration; objectivity registers; expertise; and the visibility of expert bodies. Each of these dimensions reflects some aspect of the culturally derived epistemic basis for the social application of scientific knowledge. These tests and evaluations of knowledge claims intensify when a new type of threat faces a population imminently. In this situation, pressure on scientific advisors can be intense, and attempts may be made to promote a "linear model" approach to scientific advice (e.g. Marzocchi et al., 2012), in which the role of scientists is, in theory, clearly delineated. As sociologists of scientific knowledge have shown, however, this "boundary work" (Gieryn, 1983) is not straightforward, because the distinctions between science and non-science are not obvious - especially in policy contexts. For example, scientists in policy contexts have to make judgements about issues that would not normally concern them in a laboratory setting. They have to take incomplete and uncertain knowledge and produce a coherent answer to a socially relevant not necessarily scientific - question. In a crisis, this is affected by pressures that are external to scientific process - such as the need to make evacuation decisions. The testing of knowledge claims under these circumstances are intensified prior to any event that may occur in the natural system, and may have considerable influence over subsequent responses to scientific advice. In a volcanic or seismic crisis, the timescales usually available to scientists for their own testing of knowledge are much shorter, so the uncertainty is very high, but at the same time, the advice is desperately needed by authorities. In this paper, we present a new framework, based on co-production, for approaching the civic epistemology of disasters. This analysis is based on review of the scholarly literature, and on scientific and policy reports where specified. Initially, we examine the relationship between resilience and scientific advice, drawing on the disasters literature. We then summarise the key tensions that dominate when scientists are asked to 
provide advice under uncertainty, as they seek to construct authority around incomplete knowledge.

We argue that scientific advice in environmental crises can, in some cases, be conceptualised as a "civic epistemological rupture": an event that changes the position and relationship between scientific advisory practice and the public in a specific time and place. In particular, we suggest that apparent obstacles to "pure" science in the process of risk assessment and management may be overcome by structured, civic epistemological framings and aid the co-production of social order in the disaster management process (drawing on the work of Sheila Jasanoff, 2004, 2005,2010). Studies have shown that scientific advice in volcanic crises, for example, is subject to and penetrated by similar social, political and economic considerations as scientific advice in other contexts (Donovan and Oppenheimer, 2014, 2015; Fearnley, 2013; see also for example Owens, 2005; Jasanoff, 2005). It is, however, more time-critical in environmental crises than it is in relation to biotechnology or nuclear technology - and the timescale is set by the natural environment. For effective reduction of disaster impacts, consideration must be paid to the institutional and epistemological framings of expert advice, as well as to the more common issues of public education and planning. We present a framework that aims to contribute towards a civic epistemology of disaster science.

\section{Scientific advice and increasing resilience: Why do we need a}

\section{framework?}

Disasters have been framed as "windows of opportunity" (e.g. Birkmann et al., 2010) and "catalysts" (e.g. Kreps, 1998). White (1945) noted that while natural hazards may be "acts of God", losses as a result are "largely acts of man". Hewitt (1997) identified the dangers of depending on scientific and technical approaches to disaster management, focusing instead on disasters as social processes and the reduction of social vulnerability. This approach has dominated disasters literature in recent decades (e.g. Cutter 2003; Wisner et al., 2004, 2011; Smith, 2001; Hewitt, 2013): the concept of a "natural disaster" is a contradiction in terms. Recent literature has also adopted the ecological concept of "resilience" as a means of understanding the ways in which societies deal with disasters 
121 (e.g. Adger et al., 2005; Paton, 2006). While critical, the focus on community resilience and vulnerability has arguably coexisted with a neglect of the role and nature of scientific advice in disaster management - and this is the topic we seek to address in this paper. In the case of seismic and volcanic risk assessment, the importance and difficulties - shown at L'Aquila - of applying world-class science to the problems should not be underestimated (Tilling, 2008; Gaillard and Mercer, 2013), even though it is a small part of the overall picture of disaster risk reduction (DRR). The UN ISDR defines resilience as follows:

'The ability of a system, community or society exposed to hazards to resist, absorb, accommodate to and recover from the effects of a hazard in a timely and efficient manner, including through the preservation and restoration of its essential basic structures and functions.' preparedness of local people (Paton, 2006; Paton and Johnston, 2006). However, the use of the term has become so widespread that its meanings are increasingly difficult to reconcile, particularly when combined with other Disaster Risk Reduction terms (such as vulnerability, capacity and exposure; e.g. Manyena, 2006; Alexander, 2013b, Lewis and Kelman 2010; see also Adger, 2006 and Gallopin, 2006). Alexander (2013b) suggests that the term has the potential to remain useful as long as its limitations are recognised - particularly when it is applied to complex social systems. Resilience can be used to theorise the process of disaster risk reduction, but it cannot describe it in its entirety. It offers insight into the processes of recovery and the factors on which they depend. The resilience of a society to a hazard depends on the pre-disaster infrastructure and on adaptive capacity (e.g. Pelling and High, 2005; Gaillard, 2007), and on the nature of the hazard and its impacts. The ability of critical systems to adapt to the changing circumstances can have a significant impact on the recovery process (e.g. Gaillard, 2007; Handmer, 2003). This includes the ease with which expert advice can be located and integrated into disaster risk management. 
Wisner et al (2012) and Gaillard and Mercer (2013) developed a road map for disaster risk reduction.

They identified three strands of DRR: risk assessment, dialogue and action. In each of these, the integration of local and scientific knowledges was highlighted. In the case of extreme hazards, however, where uncertainty is high, knowledge claims can become contested very rapidly and this whole process changes the nature of knowledge generation and management in a local, social context. There may be interaction between the risk assessment process and the processes of dialogue and even action within the helpful scheme of Gaillard and Mercer (2013): risk management is not in practice a linear progression. Social and political complexities affect scientific knowledge production, especially under uncertainty. While it is critical that scientists do interact with local communities prior to hazard realisation to maximise the integration of local and scientific knowledges, it is also important to note that the role of science in disaster management may also involve the negotiation of very high levels of uncertainty in the risk assessment process, alongside an anticipation of public response. This requires a consideration of epistemological issues that arise in risk assessment and in its integration with policy - something that is significantly aided by taking a co-production approach. Stakeholders may demand information on the evidence behind policies, for example, as was witnessed in the 2010 ash crisis in Europe when airlines questioned the necessity of airspace restrictions (e.g. Donovan and Oppenheimer, 2011). These issues involved uncertainty concerning scientific models and observations, as well as expert opinion. The time-critical nature of these processes during a crisis necessitates careful planning on the part of scientists and practitioners. In the next section, we discuss some insights into the science-policy process that have been made in other fields that are less time-dependent than our context. In doing so, we draw on the Science Studies literature and on perspectives from the philosophy of science.

\section{Civic epistemological ruptures: A framework for DRR} fields (e.g. Collins and Evans, 2007; Jasanoff, 2004, 2005, 2007; Nowotny et al., 2003; Brown, 2009; 
Fischer, 2010). Geographers of science have also discussed science and policy, particularly in relation to environmental knowledge controversies (e.g. Lane et al., 2011; Whatmore, 2009) and field stations (Powell, 2007). The combination of disaster studies and Science Studies enables an interrogation of the practice of science in particular places at particular times, examining its social context, methods and identity. It can contribute to policy making through the identification of the themes and patterns that emerge from such studies and that may provide insights for future planning. In the context of disaster research, this is critical in the building of resilience to manage future events. Risks from natural hazards are spatially constructed (Hewitt, 1997, 2013; November, 2004, 2008; Wisner et al., 2004; Pelling and High, 2005; Pelling and Dill, 2010), and the interaction between physical and human factors is complex: risk both transforms and is transformed by spaces (November, 2008). Indeed, attempts to quantify and assess risks do themselves have an impact on the way that risk is framed in a social context (e.g. Haynes et al., 2008), and social context can have an impact on the ways in which risk assessment is carried out, as scientists try to anticipate the critical social questions. In individual cases, the importance of the experience, judgement and political awareness of scientists in the advisory process has been demonstrated repeatedly (e.g. Hall, 2011; Haynes et al., 2008). The growing reliance on subjective risk assessment methodologies such as expert elicitation demonstrate the liminal nature of the policy interface - and can present challenges for the philosophies of individual scientists (e.g. Castanos and Lomnitz, 2002; Aspinall, 2012; Donovan et al., 2012b,c). The concept of boundary work is important here (Gieryn, 1983). Scientists have been observed to attempt to delineate their work from that of policymakers using a range of tools, including the rhetoric of objectivity and the use of quantitative assessments. In practice, however, the "boundary" between science and policy is leaky (Owens, 2005; Owens et al 2006; Eden et al., 2006; Lovbrand, 2007; Donovan and Oppenheimer, 2014 aspects of the human mind conspire to taint the pursuit of "objective" knowledge. He refers to these 
as "epistemological obstacles" - these hinder the breakthroughs in scientific discovery that are referred to as "epistemological ruptures"; and "epistemological acts" are processes that aid such ruptures $^{1}$ (see also Althusser, 1969 and Foucault, 1969, for other uses of these terms). He offers a psychoanalytical approach to understanding objective knowledge, noting that the primary obstacle to the progression of scientific thought is common sense. At the crux of these discussions is a contestation of the relationship between subjectivity and objectivity: it is the humanity, feelings and impressions of the individual that present an obstacle to scientific progression (Bachelard, 1938). In contrast, scientific advice frequently depends upon such impressions: scientists' judgements are based on their expertise but are inevitably subjective and may also depend on context (social and scientific). This liminal science may be uncomfortable and result in those participating being selfselecting. It may challenge accepted scientific methods and be forced to apply untested techniques in the service of social need. However, this can also lead to breakthroughs both in the practice of science and in its societal role (e.g. Donovan et al., 2012a; Sparks, 2007). Aspects of the psyche that Bachelard considered to be a hindrance to the progression of science ("epistemological obstacles") may actually help the progression of scientific advisory practice. For example, recent work has emphasised the importance of embracing subjectivity in science (O'Brien, 2010; Curtis, 2012). From a different perspective, the widely used method of "scenario planning" (Ringland and Schwartz, 1998; Alexander, 2000; Lindgren and Bandhold, 2002) requires a level of expert imagination something also considered an obstacle by Bachelard.

Reading Bachelard through the lens of the last thirty years of research, we could surmise that understanding the relationship between the self - complete with impressions, imaginings and interpretations - and the "object" in nature is at the heart of negotiating uncertainty in scientific advice. This is the foundation of the co-production idiom, and hints at its usefulness in bringing together the social and physical sciences. It is the expert self that has to straddle the uncertainty-

\footnotetext{
${ }^{1}$ Volcanic eruptions can, therefore, be epistemological acts through the advances that come about through the rapid acquisition of volcanological knowledge that results from them (e.g. Baxter, 2008; Donovan et al., 2013).
} 
ridden boundary between knowledge and advice - a social experience that requires social scientific analysis. Experts have to interact both with peers and with "lay people" - including local officials and populations. Bachelard viewed epistemological ruptures as positive: they advance human learning. We suggest that extreme events such as volcanic eruptions, large earthquakes and other high magnitude hazards can produce civic epistemological ruptures: they change the course of knowledge production at the science-society interface, through shared experience and learning. If this occurs efficiently, it will facilitate resilience as a part of adaptive capacity. If it fails and information is disputed, unclear or unavailable, response to the hazard will be similarly delayed and confused as expertise is assembled ad hoc.

The trial of six seismologists and a public official in Italy can be read as a civic epistemological rupture: it has shaken the ways in which scientists think about providing advice and it has brought the relationships between scientists and society in a particular place to light. In the next section, we discuss the events in more detail, focussing particularly on the wider scientific response, in which senior scientists and scientific institutions reactively strongly and quickly to a complex situation in a way that was itself not at all 'scientific' (Alexander, 2014). We show that many of the debates about L'Aquila in the broader scientific community revolve around the establishment of authority - the authority of "science", and also of particular people who practise it. This attempt to establish authority works against science because it resists the ideas of co-production and civic epistemology.

\section{Events at L'Aquila and the construction of authority}

The trial, sentencing and subsequent acquittal of six seismologists on the Major Risks Commission in L'Aquila provoked a very wide range of responses. Scientific institutions condemned the verdict. Some examples:

"It is thus incorrect to assume that the L'Aquila earthquake should have been predicted. The charges may also harm international efforts to understand natural disasters and mitigate associated risk, 
because risk of litigation will discourage scientists and officials from advising their government or even working in the field of seismology and seismic risk assessment." American Geophysical Union (AGU)

"They are clearly all eminent scientists with many years of experience in their expert fields, not novices. To charge these scientists with criminal neglect is unconscionable. The scientists did not cause the earthquakes, they could not prevent them, nor could they predict them, so how could they be guilty of manslaughter? This is a farce and they have been made scapegoats." International Association of Volcanology and Chemistry of the Earth's Interior (IAVCEI)

"We are deeply concerned. It's not just seismology which has been put on trial but all science," Charlotte, Krawczyk, Seismology division at the European Geosciences Union (EGU)

"This trial has raised huge concerns ... Because here you have a number of scientists who are simply doing their job being accused of criminal manslaughter". Tom Jordan, Southern California Earthquake Center (SCEC)

"The charges against these scientists are both unfair and naive. The basis for those indictments appears to be that the scientists failed to alert the population of L'Aquila of an impending earthquake. However, there is no way they could have done that credibly." American Association for the Advancement of Science (AAAS)

"When serving on high level advisory panels for governments and authorities, scientists have the duty to provide the state of knowledge in a comprehensive and unbiased fashion, to enable authorities to take the required mitigation actions. This cannot be achieved under the threat of public prosecution. A negative impact of this trial and sentence will be to make scientists reluctant to serve on risk advisory commissions or express expert opinions. "International Association of 
These comments hold within them several latent views about scientific advice: that reputation

("eminent scientists") is a major source of authority; that this specific incident is a trial of "all science"; that scientists on advisory panels are "unbiased"; and that science is beyond reproach. These reactions betray a positivist view of scientific knowledge and authority, much like that championed by Bachelard. The trial was widely misread as a trial of science, as has been noted by several commentators (e.g. Hall, 2011; Alexander, 2014; Yeo, 2014). The problem was that the public were reassured by a local official (also sentenced to jail time, though this has since been reduced at appeal) that there was a "favourable situation" because the small earthquakes were releasing the stress on the faultline. This was presented as the scientific viewpoint. On $31^{\text {st }}$ March 2009, a meeting of the Major Risks Commission was convened, and evidence emerged at the trial to suggest that the reason that the committee had met was that public officials wanted to calm the public down following the small earthquakes and the claims, made by a technical officer (not a seismologist) that radon gas emissions suggested there would be a major earthquake. The minutes of the meeting, published by L'Espresso magazine, state:

Alla riunione partecipano le massimo autorità scientifiche del settore sismico, in grado di fornire il quadro più aggiornato e affidabile di quanto sta accadendo.

(The greatest scientific authorities in the field of seismology are participating in the meeting, in order to provide the most up-to-date and reliable picture of what is happening.)

Thus, one of the issues that underlies the case is the construction of authority: senior scientists held in esteem by the state were asked to silence the concerns of an "amateur" - and this has continued in the aftermath (e.g. see Alexander, 2015). It is interesting to note that subsequent responses from scientists have cautioned that the case may itself lead to scientific advice being the realm of "mavericks and charlatans" who are willing to take the risk of prosecution (see Cartlidge, 2012). The responses to the verdict are also symptomatic of a defensive science that reinforces the perceived division between "science" and "non-science" as a source of authority. They were also, interestingly, 
almost entirely ignorant of the nuances of the local context (as described eloquently by Alexander,

292

293

294

295

296

297

298

299

300

301

302

303

304

305

2014): the scientists were associated with the political 'caste', which is increasingly mistrusted by the population. This also emerged in the responses of other Italian scientists to the reaction from the wider scientific community. One senior scientist wrote, in an email to a global list for volcanology ("Volcanonet") that "scientists are only able to be truly independent if they have been assigned positions purely on the basis of their scientific expertise and merit. However, if such positions are acquired based on personal bias, relationships or "association" and not on scientific competence, it is clear that the scientist loses their autonomy." There were clearly political problems within the Italian scientific community as well as between it and other groups. This paper is not concerned with the details of the indictments or the debates that have followed (e.g. Alexander, 2014, 2015;

Gabrielli and Di Bucci, 2015; Aspinall, 2011; Marzocchi, 2012). Instead, we pick up on a number of themes that are distilled from this example and from others in order to suggest a way forward for studies of scientific advice in disasters. These include the ways in which scientists involved in advice are identified, the representation of uncertainty in reporting, the social context and the governance structures involved.

Table 1 presents a brief timeline of events at L'Aquila.

\section{Date}

October 2008

March 2009

\section{Event}

Earthquake sequence starts.

Giampaolo Giuliani measures elevated levels of

radon gas and warns the authorities

$31^{\text {st }}$ March 200918.30

made by scientists:

- a sequence of earthquakes does not necessarily constitute a precursor to a larger event 


\begin{tabular}{|c|c|}
\hline & $\begin{array}{l}\text { - it is extremely difficult to forecast } \\
\text { earthquakes } \\
\text { - the only way to prepare for earthquakes } \\
\text { is to focus on improving buildings }\end{array}$ \\
\hline $31^{\text {st }}$ March 2009 (time unknown) & $\begin{array}{l}\text { De Bernadinis, a public official on the Major Risk } \\
\text { Commission, reassured the public that there was } \\
\text { no danger and, prompted by a journalist, } \\
\text { recommended his favourite wine. }\end{array}$ \\
\hline 6 April 2009 & Earthquake occurs, killing 309 people \\
\hline 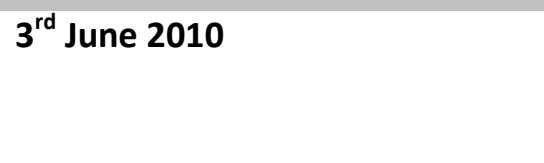 & $\begin{array}{l}\text { Indictments issued against six scientists and a } \\
\text { local official }\end{array}$ \\
\hline 25 May 2011 & Prosecution commences \\
\hline October 2012 & $\begin{array}{l}\text { Six scientists and De Bernadinis convicted of } \\
\text { manslaughter and sentenced to six years in } \\
\text { prison }\end{array}$ \\
\hline
\end{tabular}

November 2014

Convictions of six scientists overturned; De

Bernadinis' sentence reduced to two years.

Table 1. Simplified timeline of the L'Aquila trial. Sources: L'Espresso (minutes of the meeting on 31

March); Alexander, 2014, 2015; Gabrielli and Di Bucci, 2015; Cartlidge, 2011; Hall, 2011).

In the rest of this paper, we approach the civic epistemological opportunities of disasters through four key themes within a co-production framework, summarised in Figure 1 - though it should be noted that there are connections and links between and within the boxes shown in the figure. Initially, we discuss the issue of "locating expertise" - the institutional and networked context of expert advisory groups in society. This is important in disasters because disasters are time-critical. There is rarely time to assemble an expert advisory group in a crisis. We use some recent examples to illustrate this issue, which ultimately concerns the ways in which science and social order are co- 
produced around disasters. We then discuss the challenge of "representing expertise". This refers to the ways in which science is represented to stakeholders. In particular, it examines the representation of uncertainty - a major problem at L'Aquila, for example. One of the problems with uncertainty in an acute setting is that it undermines the perceived authority of science and tends to result in the rhetoric of "objectivity". The co-production of science and social order, however,

321 requires a careful framing of uncertainty. Thirdly, we address the context of expertise. Much valuable social scientific research in DRR has concerned the role of local knowledge and of local perceptions of risk. Co-production and the negotiation of civic epistemological ruptures requires an

324 awareness of the context of scientific advice, and many studies have provided insights into the 325 integration of local and scientific knowledges for DRR. Finally, we consider the issue of "governing expertise". When stakes are high, it is critical that experts' positions in relation to governance and responsibility are clear. While expertise should be accountable in a democracy, it should also be protected. 


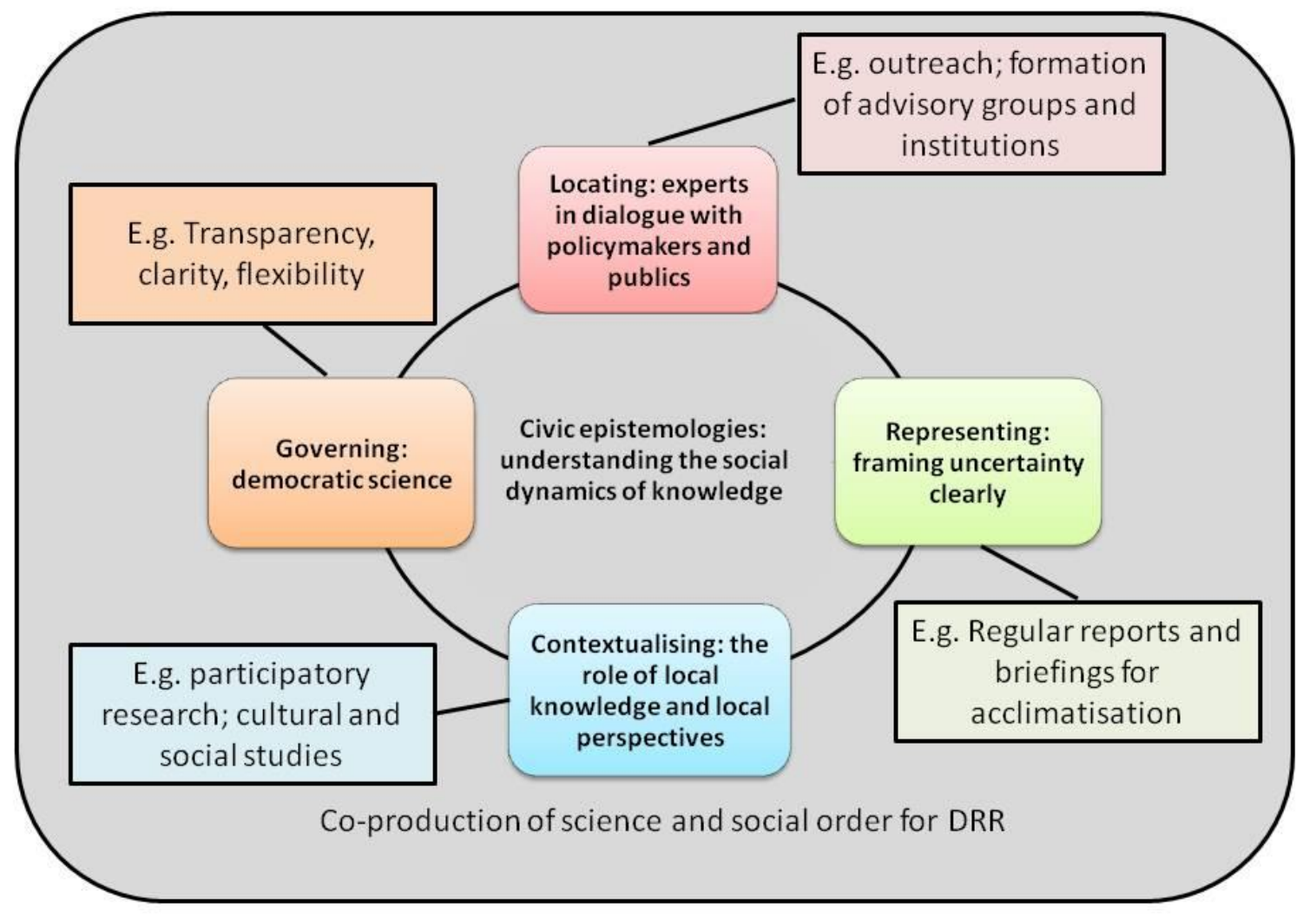

330 Figure 1. Summary of issues concerning advisory practice around disasters.

\section{The civic epistemologies of DRR}

332 In this section, we systematically review the four dimensions identified in Figure 1, using the L'Aquila example and a broad range of other examples from the literature.

Links between scientific advice and social order in the context of disasters can be demonstrated in a number of case studies. To give an example, the shock of a volcanic eruption is all-engulfing for a community that exists on the slopes of the volcano and requires rapid and effective adaptation. The volcanic eruptions on Montserrat, West Indies, began in 1995 and continued episodically until 2010. While no lava has erupted since 2010, however, the eruptions are not considered over because of 
ongoing unrest (e.g. MVO and SAC, 2014). At the onset of the eruptions, locating scientific advice was a priority, yet advice that was given prior to the imminent threat had failed to penetrate the government's consciousness: a report by Wadge and Isaacs (1988) had been sent to the local government, but was not acted upon (Donovan and Oppenheimer, 2014). This is a documented problem in volcanic disasters (e.g. Sparks, 2007; Donovan and Oppenheimer, 2011; see also Wisner et al, 2012): prior to the disaster, there may be little political will to engage with the risk or establish institutional frameworks for dealing with it (e.g. Wisner et al., 2011). In many cases, the expertise is "latent" within the scientific community and has no means to penetrate policy. Referring to Soufriere Hills and Montserrat, Fergus (2004) wrote:

There is no totally satisfactory and logical explanation for the neglect of the volcano and its potential hazards except the imprecision of volcanology as a science, the ambivalence of the predictions as a result of that imprecision, and the long time-lapse between the last eruption and $1995 .^{2}$

Fergus, a former deputy Governor of the island, felt that, given the evidence - which included several seismic crises in the twentieth century - it "should not have been a secret" (Fergus, 2004) that the volcano was reactivating. The fault lay, he felt, with the lack of uptake of the Wadge and Isaacs report by the local government. Scientific knowledge was not adequately communicated or received. Thus, the eruption came as a shock to many inhabitants, and the act of coming to terms with it was essentially one of mourning and re-identification with their reshaped island (Skelton, 2003; Donovan et al., 2011). The failure of scientific knowledge to penetrate planning was an obstacle to flexible and rapid management of the eruption in 1995 (Clay et al., 1999). There were no volcanologists on Montserrat itself, so scientists from the University of the West Indies, from universities in the UK, and from the Volcanic Disasters Assistance Program in the USA were brought in to provide the necessary information. Unfortunately, as noted above, there is a high level of uncertainty in a volcanic crisis, and in 1995 there was a lack of consensus between these groups

\footnotetext{
${ }^{2}$ The volcano had not erupted since settlement, in 1632.
} 
concerning the likely course of the eruption (Aspinall et al., 2002). This combined with a lack of institutional, legislative and political frameworks for managing the eruption, and resulted in the formation of institutions, laws and committees over a period of several years of chronic crisis (Pattullo, 2000; Clay et al., 1999). There were also differences in the pace of acquiring scientific structures (which occurred fairly rapidly) and formalising them (which took several years - the volcano observatory was formalised by government Act in 1999 and the scientific advisory committee in 2003, partly in response to fear of litigation; Donovan et al., 2012d).

As noted above, critics of the scientists who were convicted in the court cast concerning the L'Aquila earthquake argued that the selection of these scientists was politically motivated, and that their political allegiances impacted their judgement (e.g. Hall, 2011). The ways in which governments select scientists are varied, but often involve informal networks, or key, government-backed scientific institutions (e.g. Jasanoff, 2005; Donovan and Oppenheimer, 2012). This snowball-like method of selection depends upon the integrity of those involved in suggesting the names of people who may be more appropriate - particularly in time-critical contexts. The source of scientific authority must also be considered: Jasanoff (2005) notes that in the UK, choice of experts may depend as much on previous service to society as on knowledge. There are also some important differences between nations concerning how authority is constructed, and this relates very closely to the accessibility of expert advice. In Iceland, for example, volcano monitoring data are publically available (e.g. Bird et al., 2008), allowing members of the public to draw conclusions from the same data as the scientists. Reports of the scientific interpretations of the volcanic eruptions were readily available online. In the UK, however, the "ash crisis" of 2010 came as a surprise for which the government was not prepared (Donovan and Oppenheimer, 2011, 2012). It instigated a "Scientific Advisory Group in Emergencies" (the SAGE mechanism) to provide advice, but the selection of SAGE members and the content of the meetings themselves were not clear nor public. In 2011, the secrecy surrounding the SAGE was criticised by the Select Committee (House of Commons, 2011; 
Donovan and Oppenheimer, 2012): there was insufficient clarity about the information on the basis of which decisions about volcanic ash had been taken, and a breakdown of communication between scientists and government about the risk prior to the eruption (Oppenheimer, 2010). Minutes of SAGE meetings have since been published, and a strength of the SAGE mechanism is its flexibility.

These examples demonstrate that advisory mechanisms for disasters have to be both pre-emptive and responsive. There is continuous dialogue between the social progression of a disaster and the scientific advisory process, as decisions and the knowledge-claims on which they are based are questioned. Other forms of knowledge and interpretation are frequently applied in the knowledgetesting process. These can include past experience, local knowledge, (post)colonial discourses, changes in relationship between people and land, people flows and networks, and cultural memory (e.g. Cashman and Cronin, 2008). All of these issues impact social and scientific knowledge production and require sensitivity (e.g. Allen, 2007).

The involvement of international scientific advisors is common in seismic and volcanic hazard assessment. Examples of this include the provision of advice from Japanese scientists to Iranians following the Bam earthquake in 2003 and the involvement of the USGS Volcanic Disasters Assistance Programme (VDAP) in a number of volcanic crises, including Pinatubo (Newhall and Punongbayan, 1996), Merapi in 2010 (Surono et al, 2012) and indeed on Montserrat in 1995, albeit briefly (Aspinall et al., 2002). In each of these cases, local knowledge was combined with the experience and knowledge of the international teams in order to manage a local or regional-scale event. The presence of scientists from multiple cultures inevitably provides differing perspectives, especially if a local culture has a much greater awareness of the human geography of the region. A key lesson might thus be the importance of reflexivity in science: awareness of the potential for

411 social circumstances or personal experience to affect risk judgements. A further, critical issue for 412 other contexts might be the involvement of multiple scientific agencies with different structures and experiences. These circumstances require a clear, transparent and systematic approach for 
identifying and gathering appropriate experts in emergencies, and a flexible system for incorporating different knowledges and reaching out to different groups (Figure 1).

\section{Representing expertise: framing, objectivity and boundary work}

417 This section draws on philosophy of science and probability to examine the process of scientific risk

418 assessment - often a key part of the advisory process. It also examines the reporting and framing of

419 such assessments, arguing that the representation of expert advice is a key dimension of the civic epistemology of disasters (see Figure 1). This may be particularly challenging in volcanic and seismic risk assessment, because of low probabilities associated with high impacts, and disagreement between experts concerning the most effective methodology. At L'Aquila, for example, there were claims, after the event, that the methods used in seismic hazard assessment were inadequate or failed to use all available knowledge. These issues are actively debated within risk assessment discourses in both seismology (e.g. Castanos and Lomnitz, 2002; Marzocchi and Zechar, 2011; Jordan, 2013) and in volcanology (Donovan et al., 2012b,c; Marzocchi et al., 2012). Furthermore, unpopular decisions may lead to public interrogation of scientific method and the undermining of scientific advice. This occurred to a degree during civil cases brought in Montserrat in 2002-3 (Donovan et al, 2012d): local people criticised the scientists because of an evacuation that lasted for nine months. This led to a civil case against the Governor of the island, and to negative relationships between scientists and society (e.g. Aspinall, 2011). Communication strategies are thus particularly important, and in a democratic society these include transparency about both knowledge and nonknowledge in scientific reports.

A characteristic of volcanic and seismic hazards is the high uncertainty that surrounds them. This invariably impacts the use of scientific advice - and is a critical element of its communication. For example, Haynes et al (2008) found that Montserratians were more accepting of science when they had grasped that it could not give the answers they wanted. Many decisions have to be made on the 
basis of best estimates, frequently expressed as probabilities. The epistemological status of probability is problematic (Hacking, 2001; Popper, 1959), but the provision of probabilistic estimates nevertheless constitutes a form of knowledge-claim because it asserts that certain events are thought to be more or less likely based on fragmentary knowledge. This liminal form of knowledge is essential in risk management: quantitative assessment greatly facilitates the monitoring of whether or not risk has increased from one period to the next, for example. Nevertheless, it also requires qualitative framing so that the claim and the reasoning behind it - the true scope of the fragmentary knowledge - are transparent (Donovan et al., 2014). This involves appropriate use of language. For example, scientific definitions tend to oppose "objective" and "subjective" in ways that are not helpful for transparency or the progression of scientific advice (Aspinall, 2012; Donovan et al., 2012b): as Kuhn (1977) argued, the concepts are not opposed but rather define different ideas.

Further to this, when knowledge claims are controversial, scientists may be "subjectivised" by the public - arguably a similar phenomenon to L'Aquila. Scientists may be torn between defending the "objectivity" of science and acknowledging the uncertainty inherent in the natural system. This points to two important aspects of managing non-knowledge: transparency and awareness of positionality (reflexivity; Donovan et al., 2014). Facilitating the representation of expertise within the social context is an important aspect of risk management, and involves acknowledgement of the limitations of knowledge as well as its implications. Disasters can be negotiated through adaptive methodologies for representing uncertainty and risks, and by the continued examination of claims made by expert groups. Social scientific input into the presentation and communication of scientific advice would be extremely beneficial here: the framing of expert advice is crucial in preventing situations like L'Aquila, as has been demonstrated repeatedly in Science Studies (e.g. Irwin, 2001; Miller, 2000; Hajer,2003). It would also ensure that policymakers and the public are not misled about the uncertainty in science. The importance of representing science and uncertainty accurately has been witnessed in other aspects of environmental geography (such as climate change), and human 
geographers are ideally positioned to carry out forensic research on past extreme events and develop best practice guidelines that are effective.

\section{Contextualising expertise: knowledge identities and geographies}

466 Civic epistemological thresholds frequently involve the management of a range of cultures and identities, all of whom are experiencing the event in different ways. This can include past experience, local knowledge, (post)colonial discourses, changes in relationship between people and land, people flows and networks, and cultural memory (e.g. Cashman and Cronin, 2008). All of these issues impact social and scientific knowledge production and require sensitivity. One important emerging method for the integration of such knowledges is Participatory Mapping (Cadag and Gaillard, 2012), and other examples are given by Lane et al (2011): local and scientific stakeholders interacting to learn from past events and prepare for the future. However, in the case of very low probability events, or those where there is a high dependence on experts, it is critical that all information is available to governments very quickly. While formal participatory methods may not be readily available, particularly in a crisis, some degree of engagement with the public is helpful for establishing both authority and accountability (e.g. Haynes et al., 2008). There are thus two aspects to this theme: the cultures and identities of experts and those of the at-risk community.

Taking this further, we might suggest that the presentation and application of scientific advice also requires input from social scientific studies of risk perception and communication in these different contexts (e.g. Douglas and Wildavsky, 1982; Sjoberg, 2000; Slovic, 2000). For example, Gaillard (2008) noted that people living close to Mount Pinatubo perceived volcanic risks as high, but showed that in spite of this, many will take risks because they are more concerned with the daily challenge of mitigating poverty. Risk tolerability ${ }^{3}$ varies in space and time: there is too much complication from

\footnotetext{
${ }^{3}$ Risk tolerability refers to the level of risk that an individual or group is willing to accept. It has been shown to vary according to the nature of the risk, as well as the socio-economic status and characteristics of the individual or group (e.g. Aven and Renn, 2009).
} 
non-numerical sources such as cultural conditioning (cf Kahan et al., 2009). The implication from this argument is that risk scales ${ }^{4}$ could easily become chaotic, being socially, politically, culturally, historically and geographically specific - an example being the particular case of small islands (e.g. Pelling and Uitto, 2001; Tompkins, 2005). Insight into the types of risks that people in a community face on a regular basis, their views about different risks and their trust in different institutions can inform risk assessments, both through addressing relevant questions and through making comparisons with well-known risks. Furthermore, they inform communication and outreach activities that help to build resilience (see for example Ben Wisner's work on social capital in megacities, Wisner 2003).

Risk-taking in a volcanic or seismic environment is ultimately a function of space and time (Massey, 1999): it is human and physical, but not merely in definition; it is on the interface between human and physical in its realisation by communities and by scientists. Understanding the relationship between knowledge, expertise and experience in different cultural contexts provides insight into the risk communication process during the negotiation of disasters. Risk communication and perception studies are important in understanding the differences between cultures, and participatory methods that include scientists, officials and members of the public may be particularly important in building social relationships prior to hazard realisations (see for comparison O'Brien et al., 2008; Brown and Damery, 2002; Morss et al., 2005).

\section{Governing expertise: responsibility and accountability}

The previous sections have commented on the types of expertise and (non-)knowledge claim that may be made during a crisis and their relationship to specific geographies. This section returns to the issue raised in the introduction about responsibility: how is the relationship between science and society governed? Again, this is geographically defined and the level of legal protection enjoyed by

\footnotetext{
${ }^{4}$ Such as the UK Chief Medical Officer's scale, which ranks specific values representing risks as "high", "medium", "low" etc.
} 
expert advisors varies around the world (Aspinall, 2011). It may also not be clear to scientists at the time of accepting an advisory role - particularly during a crisis. The complexity of governments, and the relationships between advisory structures, decision-makers and civil officials, may vary considerably with geography (Donovan and Oppenheimer, 2015). For example, while Iceland has a permanent structure for advice from scientists concerning earthquake and volcanic hazards, such a structure does not exist in the UK - resulting in the invocation of the "SAGE" mechanism in 2010 (Donovan and Oppenheimer, 2012). This was effective, but took time to assemble. On Montserrat, too, the complexity of a colonial governance structure presented a challenge for scientists (Donovan et al., 2013). The UK-appointed Governor had personal responsibility for the lives of the people on

517 the island, and in 1996 passed a law allowing mandatory evacuations. Since these evacuations were 518 based on scientific advice and led to lawsuits, scientists had to give evidence and there were 519 concerns about their legal status (Aspinall and Sparks, 2004; Donovan et al., 2012d). There is a balance to be achieved between ensuring that scientists acting in good faith are protected, and that there is a level of accountability.

In terms of accountability, the role of scientists in a democracy has been scrutinised both in the Science Studies literature (e.g. Wynne, 1989, 1992; Shackley and Wynne, 1995, 1996; Jasanoff, 2004, 2005, 2007; Brown, 2009; Fischer, 2010) and in the sociological studies of risk (e.g. Beck, 1992; Giddens, 1999). The knowledge that scientists (may) possess and that governments and publics need gives the former a power that potentially threatens the democratic governance of risks (Beck, 1992).

527 This may be exacerbated in an emergency, when there is a clear need to identify experts rapidly and dependence on experts is very high. This can lead to blurred boundaries, since, for example, advice from a scientist that a particular area is unsafe is very likely to result in evacuation even if there are very high uncertainties - and scientists may be blamed (Aspinall, 2011; Donovan et al., 2012d). Conversely, scientists themselves may politicise their advice (e.g. Pielke, 2004). Clarity surrounding 
the role of experts as advisors is crucial, both for their security and for the management of postdisaster criticism.

Responsibility in the context of scientific advice also rests with citizens, however, since there is often a choice in buying land in known hazardous areas. This is a key distinction in hazards research, because urban development has frequently preceded the identification of hazardous areas.

Responsibility in this context is intensely local. Expertise becomes embedded in new ways in an intense situation (Donovan et al., 2013). This depends in part on its role or institutional framing prior to the shock, but also on particular local political, social and scientific issues that arise in a crisis and that require flexible institutional practices. There is therefore a balance between ensuring that science is in some way accountable, and ensuring that expert advisors are legally protected (e.g. Alexander, 2014; Aspinall, 2011).

\section{3}

\section{Conclusions: Science Studies approaches for increasing resilience to}

\section{environmental risks}

The focus on reducing social vulnerability prior to disasters has tended to ignore or underestimate the importance of scientific input, and to suggest that "hazard" is only the realm of scientists. Thus the traditional formulation, risk = hazard x vulnerability (sometimes with terms for "mitigation", "capacity" and "exposure"), can result in a misleading separation of scientific and social scientific aspects of disaster research because the framing of the hazard affects vulnerability. The extensive social scientific focus on vulnerability has produced some very important results, but it has generally failed to consider the epistemological implications of disasters and the co-production of science and social order that occurs in their management. To do so requires a coherent understanding of the dimensions of civic epistemology and the ways in which scientists construct their authority - a rich field for social science. Disasters produce civic epistemological ruptures - changes in the ways that societies test and use knowledge. The relationships between science, scientists, decision-making and 

society clearly defined the events at L'Aquila. It is these relationships that dominate in the management of disasters, and they are themselves dependent in part on the way that knowledge is produced, tested and applied in a context of high uncertainty and short timescales.

The framework presented in this paper has focussed on four dimensions of scientific advisory practice for disasters. There were problems with all of these dimensions at L'Aquila. Scientific advice was kept aloof from the public in an attempt to follow a "linear model" and the selection of experts was criticised, advice was not widely trusted, the uncertainty on the likelihood of an earthquake was not adequately or appropriately communicated, and the accountability and responsibility of different groups was not clear. L'Aquila is also an important opportunity, however, to learn from the problems that arose and to formulate strategies for the management of scientific advice in timecritical contexts. We have used this example, together with other recent volcanic and seismic crises, to demonstrate the importance of co-production as a framework for disaster management, and to show some of the dimensions of the civic epistemology that this involves. The totality of disasters, particularly volcanic eruptions and earthquakes, does make them a special case - an "act" by the natural system that is identifiable in time and space but whose impacts may be much less well defined. The stakes in these circumstances can be very high indeed, but their rarity is such that preparations may not have been made in advance. Increased awareness of the complexity of the "local knowledge" and "scientific knowledge" that are discussed regularly in the disaster management literature would aid the construction of meaningful institutional practices and flexibility prior to disasters. In volcanic eruptions in particular, there will always be a high dependence on scientific advice; ensuring and understanding its reliability, authority and integration with social learning is thus of paramount importance. The role of place, spatial constructions of risk and cultural context in framing disaster risk provides a rich opportunity for multidisciplinary studies led by geographers. Human and physical approaches, though epistemologically and ontologically diverse, can be combined in the context of advisory science. However, the tendency of geographers 
581 to bifurcate in this way can also be detrimental, and this is closely reflected in the hazard -

582 vulnerability split in DRR.

583 In order to take DRR forward, then, it is necessary for human and physical geographers, physical and 584 social scientists, to be explicit about their epistemological frameworks. This has been realised in part 585 by several recent projects, but ontologically and epistemologically the two sides frequently remain 586 embedded in their scientific or social scientific disciplinary training. Yet this is changing within 587 geographical studies. Lane et al (2011) describe an example of this in flood risk management, 588 demonstrating the potential for collaborations (see also Morss et al., 2005 and Demeritt et al., 589 2010). In the context of DRR, these collaborations have to be transdisciplinary (involving 590 policymakers, the public and NGOs) in a bottom-up-top-down approach (e.g. Wisner et al., 2012).

591 Furthermore, the Understanding the practice of scientific advice prior to, during and after disasters 592 will not prevent their occurrence, but could help to ensure that they are manageable rather than 593 crippling.

Acknowledgements

595 AD gratefully acknowledges support from a Leverhulme Trust Early Career Fellowship, part-funded 596 by the Isaac Newton Trust, University of Cambridge. AD would also like to thank Professor Susan Owens for productive and enjoyable discussions.

Adger WN Hughes TP Folke C Carpenter SR Rockstrom J 2005 Social-ecological resilience to coastal disasters Science 3091036-9

Adger WN 2006 Vulnerability Global environmental change 16(3) 268-281 
Alexander D 2010 The L'Aquila earthquake of 6 April 2009 and Italian Government policy on disaster response Journal of Natural Resources Policy Research 2 325-342

Alexander D 2013 An evaluation of medium-term recovery processes after the 6 April 2009 earthquake in L'Aquila Central Italy Environmental Hazards 12 60-73

Alexander D 2013b Resilience and disaster risk reduction: an etymological journey Natural Hazards and Earth System Sciences Discussions 1 1257-1284

Alexander D E 2014 Communicating earthquake risk to the public: the trial of the "L'Aquila Seven" Natural Hazards, 72(2), 1159-1173.

Alexander D E 2015 Reply to a comment by Franco Gabrielli and Daniela Di Bucci:“Communicating earthquake risk to the public: the trial of the 'L'Aquila Seven'" Natural Hazards, 75(1), 9991003.

Allen B L 2007 Environmental justice and expert knowledge in the wake of a disaster Social studies of science $37(1)$ 103-110

Althusser L 1969 For Marx trans Ben Brewster London New Left Books 1969

Aspinall WP 2011 Check your legal position before advising others Nature 477:251

Aspinall WP 2012 Comment on Donovan et al 2012 "Social Studies of Volcanology expert advice and knowledge generation on active volcanoes" Bulletin of Volcanology

Aspinall WP Loughlin SC Michael FV Miller AD Norton GE Rowley KC Sparks RSJ and Young SR 2002 The Montserrat Volcano Observatory: its evolution organization role and activities Geological Society London Memoirs 21 (1)71-91

Aspinall WP and Sparks RSJ 2004 Volcanology and the law IAVCEI News 1(4)

Aven T Renn O 2009 The role of quantitative risk assessments for characterizing risk and uncertainty and delineating appropriate risk management options, with special emphasis on terrorism risk. Risk Analysis, 29(4), 587-600.

Bachelard G 1938 La formation d'esprit scientifique Reproduced Paris Vrin 2000 
Bird D Roberts MJ Dominey-Howes D 2008 Usage of an early warning and information system Website for real-time seismicity in Iceland Natural Hazards 47(1) 75-94

Birkmann J Buckle P Jaeger J Pelling M Setiadi N Garschagen M Fernando N and Kropp J 2010 Extreme events and disasters: a window of opportunity for change? Analysis of organizational institutional and political changes formal and informal responses after megadisasters Natural Hazards 55(3):637-655

Brown MB 2009 Science in democracy Expertise institutions and representation Cambridge Mass MIT Press

Brown JD and Damery SL 2002 Managing flood risk in the UK: towards an integration of social and technical perspectives Transactions of the Institute of British Geographers 27 (4)412-426

Cadag JRD and Gaillard JC 2012 Integrating knowledge and actions in disaster risk reduction: the contribution of participatory mapping Area 44(1):100-109

Cartlidge E 2011 Quake experts to be tried for manslaughter. Science, 332(6034), 1135-1136.

Cashman KV and Cronin SJ 2008 Welcoming a monster to the world: Myths oral tradition and modern societal response to volcanic disasters Journal of Volcanology and Geothermal Research $176(3) 407-418$

Castanos H Lomnitz C 2002 PSHA: is it science? Engineering Geology 66 315-317

Clay EB Barrow C Benson C Dempster J Kokelaar BP Pillai N and Seaman J 1999 An evaluation of $H M G$ 's response to the Montserrat volcanic emergency London Department for International Development

Collins H and Evans R 2007 Rethinking expertise Chicago University of Chicago Press

Curtis A 2012 The science of subjectivity Geology 40(1) 95-96

Cutter SL 2003 The vulnerability of science and the science of vulnerability Annals of the Association of American Geographers 93 (1)1-12

Demeritt D Nobert S Cloke H \& Pappenberger F 2010 Challenges in communicating and using ensembles in operational flood forecasting Meteorological applications 17(2) 209-222 
Donovan A and Oppenheimer C 2014 Science, policy and place in volcanic disasters: Insights from Montserrat. Environmental Science and Policy 39:150-161.

- - 2012 Governing the lithosphere: Insights from Eyjafjallajökull concerning the role of scientists in supporting decision-making on active volcanoes Journal of Geophysical Research 117 (B3)B03214

- - 2011 Commentary The 2010 Eyjafjallajökull eruption and the reconstruction of geography Geographical Journal 1774-11

Donovan A Oppenheimer C and Bravo M 2012a Social studies of volcanology: knowledge generation and expert advice on active volcanoes Bulletin of Volcanology 74 (3)677-689

- - - 2012b Reply to comment from WP Aspinall on Donovan et al 2012 Social Studies of Volcanology Bulletin of Volcanology

- - 2012c The use of belief-based probabilistic methods in volcanology: scientists' views and implications for risk assessment Journal of Volcanology and Geothermal Research

- - -2012d Contested boundaries: Delineating the safe zone on Montserrat Applied Geography 35(1) 508-514

Donovan A Bravo M and Oppenheimer C 2013 Co-production of an institution: Montserrat Volcano Observatory and the social dependence on science Science and public policy 40(2) 171-186

Donovan A Oppenheimer C and Bravo M 2014 Reflexive volcanology: 15 years of communicating risk and uncertainty in scientific advice on Montserrat. Geological Society, London, Memoirs, 39(1), 457-470.

Doubleday R 2007 Organizing accountability co-production of technoscientific and social worlds in a nanoscience laboratory Area 39166

Douglas M and Wildavsky A 1982 How Can We Know the Risks We Face? Why Risk Selection Is a Social Process Risk Analysis 2 (2)49

Eden S Donaldson A Walker GP 2006 Green groups and grey areas: scientific boundary work, NGOs and environmental knowledge. Environment and Planning A, 38(6), 1061-1076. 
Fearnley CJ 2013 Assigning a volcano alert level: negotiating uncertainty, risk, and complexity in decision-making processes. Environment and Planning A, 45(8), 1891-1911.

Fergus HA 2004 Montserrat History of a Caribbean colony Oxford Macmillan

Fischer F 2010 Democracy and expertise Reorienting policy inquiry Oxford Oxford University Press Foucault M 1969 The archaeology of knowledge Abingdon Routledge

Gabrielli F Di Bucci D 2015 Comment on “Communicating earthquake risk to the public: the trial of the 'L'Aquila Seven'” by David E. Alexander. Natural hazards 75(1), 991-998.

Gaillard JC 2007 Resilience of traditional societies in facing natural hazards Disaster Prevention and Management 16(4):522-544

Gaillard JC 2008 Alternative paradigms of volcanic risk perception The case of Mt Pinatubo in the Philippines Journal of Volcanology and Geothermal Research 172(3-4) 315

Gaillard JC and Mercer J 2013 From knowledge to action Bridging gaps in disaster risk reduction Progress in Human Geography

Gallopín GC 2006 Linkages between vulnerability resilience and adaptive capacity Global Environmental Change 16(3):293-303

Giddens A 1999 Runaway world How globalisation is reshaping our lives London Profile Books Gieryn TF 1983 Boundary-work and the demarcation of science from non-science: Strains and interests in professional ideologies of scientists American sociological review, 781-795.

Government Office for Science 2011 Blackett Review of High Impact Low Probability Risks London GO-Science

Hacking I 2001 An introduction to probability and inductive logic Cambridge Cambridge University Press

Hajer M 2003 A frame in the fields: policymaking and the reinvention of politics. In Hajer M Wagenaar H (eds) Deliberative Policy Analysis Cambridge: Cambridge University Press, 88110 
Handmer J 2003 Adaptive capacity: what does it mean in the context of natural hazards In Smith J Klein RJT and Huq S eds Climate change adaptive capacity and development London Imperial College Press 51-70

Haynes K Barclay J and Pidgeon N 2008 Whose reality counts? Factors affecting the perception of volcanic risk Journal of Volcanology and Geothermal Research 172 (3-4):259

Hewitt K 1997 Regions of risk A geographical introduction to disasters London Longman

Hewitt K 2013 Environmental disasters in social context: toward a preventive and precautionary approach Natural Hazards 66(1):3-14

House of Commons 2011 Scientific advice and evidence in emergencies, House of Commons Science and Technology Committee Third Report of Session 2010-2011.

Hulme M 2009 Why we disagree about climate change Understanding controversy inaction and opportunity Cambridge Cambridge University Press

Irwin A 2001 Constructing the scientific citizen: science and democracy in the biosciences. Public understanding of science, 10(1), 1-18.

Jasanoff S (ed) 2004 States of Knowledge The co-production of science and social order (Abingdon Routledge)

Jasanoff S 2005 Designs on Nature Science and democracy in Europe and the United States Princeton Princeton University Press

Jasanoff S 2007 Technologies of humility Nature 450:33

Jasanoff S 2010 A new climate for society Theory, Culture \& Society 27(2-3), 233-253.

Jordan TH 2013 Lessons of L'Aquila for operational earthquake forecasting Seismological Research Letters $84(1): 4-7$

Kahan DM Braman D Slovic P Gastil J and Cohen G 2009 Cultural cognition of the risks and benefits of nanotechnology Nature Nanotechnology 4 (2)87

Kreps GA 1998 Disaster as systemic event and social catalyst In Quarantelli E ed What is a disaster? Perspectives on the question 31-55 
Kuhn T 1977 Objectivity value judgement and theory choice In The essential tension Studies in scientific tradition and change ed T Kuhn 320-329 Chicago University of Chicago Press

Lane SN Odoni N Landström C Whatmore SJ Ward N and Bradley S 2011 Doing flood risk science differently an experiment in radical scientific method Transactions of the Institute of British Geographers 36(1)15-36

Lewis J and Kelman I 2010 Places, people and perpetuity: community capacities in ecologies of catastrophe. ACME: an international e-journal for critical geographies 9(2):191-220.

Lindgren M \& Bandhold H 2002 Scenario planning The link between future and strategy New York Palgrave Macmillan

Lövbrand E 2007 Pure science or policy involvement? Ambiguous boundary-work for Swedish carbon cycle science Environmental Science and Policy 10(1), 39-47.

Manyena SB 2006 The concept of resilience revisited Disasters 30(4):434-450

Marzocchi W Newhall C and Woo G 2012 The scientific management of volcanic crises Journal of Volcanology and Geothermal Research 247-248:181-189

Marzocchi W 2012 Putting science on trial Physics World

Marzocchi W and Zechar JD 2011 Earthquake Forecasting and Earthquake Prediction: Different Approaches for Obtaining the Best Model Seismological Research Letters 82:442-448

Massey D 1999 Space-Time 'Science' and the Relationship between Physical Geography and Human Geography Transactions of the Institute of British Geographers 24(3):261

Morss R E Wilhelmi O V Downton M W and Gruntfest E (2005) Flood risk uncertainty and scientific information for decision making lessons from an interdisciplinary project Bulletin of the American Meteorological Society 86(11):1593-1601

MVO and SAC (Montserrat Volcano Observatory and the Scientific Advisory Committee) 2014 Report of the $19^{\text {th }}$ Scientific Advisory Committee on Montserrat Volcanic Activity, based on a meeting held between September $22^{\text {nd }}$ and $25^{\text {th }}$ 2014. Montserrat Volcano Observatory. 
November V 2004 Being close to risk From proximity to connexity International Journal of Sustainable Development 7:(3)273-286

- - 2008 Spatiality of risk Environment and Planning A 40:(7)1523-1527

Nowotny H Scott P and Gibbons M 2001 Re-Thinking Science Knowledge and the public in an age of uncertainty Cambridge Polity Press

O'Brien K 2010 Responding to environmental change: A new age for human geography? Progress in Human Geography 35(4):542-549

Pelling M and Dill K 2010 Disaster politics: tipping points for change in the adaptation of

O’Brien K Sygna L Leichenko R Adger WN Barnett J Mitchell T Schipper L Tanner T Vogel C and Mortreux C 2008 Disaster risk reduction climate change adaptation and human security Report prepared for the Royal Norwegian Ministry of Foreign Affairs by the Global Environmental Change and Human Security Project GECHS Report 3

Oppenheimer C 2010 We told you so! Reflections on the 'ashpocalypse" Elements 2010

Owens S 2005 Making a difference? Some perspectives on environmental research and policy. Transactions of the Institute of British Geographers 30(3), 287-292.

Owens S Petts J Bulkeley H 2006 Boundary work: knowledge, policy, and the urban environment. Environment and Planning C, 24(5), 633.

Paton D 2006 Disaster resilience integrating individual community institutional and environmental perspectives In Paton D Johnston D eds Disaster resilience An integrated approach Springfield Charles C Thomas Publisher:306-19

Paton D and Johnston DM (Eds) 2006 Disaster resilience an integrated approach Springfield Charles C Thomas Publisher

Pattullo P 2000 Fire from the mountain The tragedy of Montserrat and the betrayal of its people London Constable sociopolitical regimes Progress in Human Geography 3421 
Pelling M and High C 2005 Understanding adaptation: What can social capital offer assessments of adaptive capacity? Global Environmental Change 15 (4)308-319

Pelling M and Uitto JI 2001 Small island developing states: natural disaster vulnerability and global change Global Environmental Change Part B Environmental Hazards 3(2):49-62

Pidgeon N and Fischhoff B 2011 The role of social and decision sciences in communicating uncertain climate risks Nature Climate Change 1(1):35-41

Pielke Jr RA 2004 When scientists politicize science: making sense of controversy over The Skeptical Environmentalist Environmental Science \& Policy 7:405-417

Popper K 1959 (German original 1935) The logic of scientific discovery Abingdon Routledge

Powell RC 2007 Geographies of science: histories localities practices futures Progress in Human Geography 31(3):309-329

Ringland G and Schwartz PP 1998 Scenario planning Managing for the future Hoboken John Wiley \& Sons

Sarewitz D 2004 How science makes environmental controversies worse Environmental Science \& Policy 7:385-403

Shackley S and Wynne B 1995 Global climate change: The mutual construction of an emergent science-policy domain Science and Public Policy 22 (4)218-230

- - 1996 Representing Uncertainty in Global Climate Change Science and Policy BoundaryOrdering Devices and Authority Science Technology \& Human Values 21 (3)275-302

Sjoberg L 2000 Factors in risk perception Risk Analysis 201-11

Skelton T 2000 Political uncertainties and natural disasters: Montserratian identity and colonial status Interventions International Journal of Post-Colonial Theory 2:103-117

Slovic P 2000 The perception of risk London Earthscan

Smith K 2001 Environmental hazards assessing risk and reducing disaster Routledge

Sparks RSJ 2007 Use the calm between the storms Nature 450:354

Surono et al 2012 The 2010 explosive eruption of Java's Merapi volcano-A '100-year' event Journal 
Tilling RI 2008 The critical role of volcano monitoring in risk reduction Advances in Geosciences 14 3-

Tompkins EL 2005 Planning for climate change in small islands: Insights from national hurricane preparedness in the Cayman Islands Global Environmental Change 15(2)139-149

Wadge G and Isaacs M 1988 Mapping the volcanic hazards from the Soufriere Hills Volcano Montserrat West Indies using an image processor Journal of the Geological Society London

Whatmore S J 2009 Mapping knowledge controversies: science democracy and the redistribution of expertise Progress in Human Geography 3 (5):587-598

White G F (1945) Human adjustment to floods a geographical approach to the flood problem in the United States (No 29) Chicago University of Chicago

Wisner B Blaikie P Cannon T and Davis I 2004 At risk Natural hazards people's vulnerability and disasters London Routledge

Wisner B Kent G Gaillard JC et al 2011 Political will for disaster reduction: What incentives build it and why is it so hard to achieve? A contribution to the Review of the draft GAR 2011

Wisner B Gaillard JC and Kelman I 2012 Handbook of hazards and disaster risk reduction London Routledge

Wisner B 2003 Disaster risk reduction in megacities: making the most of human and social capital. Building Safer Cities: The Future of Disaster Risk, Washington DC.

Wynne B 1989 Sheepfarming after Chernobyl: A case study in communicating scientific information Environment 31(2):33-39

- - 1992 Uncertainty and environmental learning: Reconceiving science and policy in the preventive paradigm Global Environmental Change 2(2):111-127 
839

840

841 